\title{
Triggered Lightning Testing of an Airport Runway Lighting System
}

\author{
Mirela Bejleri, Vladimir A. Rakov, Fellow, IEEE, Martin A. Uman, Fellow, IEEE, Keith J. Rambo, \\ Carlos T. Mata, Member, IEEE, and Mark I. Fernandez
}

\begin{abstract}
The interaction of rocket-triggered lightning with an airport runway lighting system has been studied. The lighting system included a buried counterpoise with attached vertical ground rods for protection of the series lighting cable from lightning. Experimental data for voltages and currents at various locations in the runway lighting system due to direct lightning strikes are presented along with the causative lightning current. The data include the first measurements of the responses of an underground bare conductor (counterpoise) to direct lightning strikes. These measurements can serve as ground truth for the testing of the validity of various counterpoise models.
\end{abstract}

Index Terms-Airport runway, counterpoise, ground rods, lighting system, lightning protection, triggered lightning.

\section{INTRODUCTION}

$\mathbf{T}$ HE EXPERIMENTS presented in this paper were conducted in 1997-1998 at the International Center for Lightning Research and Testing (ICLRT) at Camp Blanding, Florida (e.g., Uman et al. 1997; Rakov et al. 1998) [1], [2]. The ICLRT is an outdoor facility that occupies an area of about $1 \times 1 \mathrm{~km}^{2}$ and is located about $40 \mathrm{~km}$ north-east of Gainesville (home of the University of Florida). The ICLRT was constructed in 1993 for studying various aspects of lightning and lightning protection using artificially-initiated (triggered) lightning. The purpose of the experiment described here was to study the interaction of lightning with the airport lighting system shown in Fig. 1. The system was subjected to a total of 16 lightning strikes, 12 of which contained one or more return strokes. The total number of return strokes was 47 (24 in 1997 and 23 in 1998). Lightning current injection points were (1) the pavement, (2) one of the stake-mounted lights, (3) the counterpoise, and (4) the ground directly above the counterpoise or between the counterpoise and the edge of pavement. The system was energized using a generator and a current regulator for some of the tests and unenergized for others. The total lightning current and the currents and voltages at various points on the lighting system were measured.

Manuscript received January 27, 2003. revised March 31, 2003; This work was supported in part by the Florida Department of Transportation and in part by the National Science Foundation.

M. Bejleri is with the iDEN Subscriber Division, Motorola, Inc., Plantation, FL 33322 USA (e-mail: bemirela@yahoo.com).

V. A. Rakov, M. A. Uman, and K. J. Rambo are with the Department of Electrical and Computer Engineering, University of Florida, Gainesville, FL 32611-6130 USA (e-mail: rakov@ece.ufl.edu; uman@ece.ufl.edu; rambo@tec.ufl.edu).

C. T. Mata is with ASRC Aerospace, Kennedy Space Center, FL 32899-0001 USA (e-mail: cm@ieee.org).

M. I. Fernandez is with the U.S. Department of Defense, Fort Meade, MD 20755 USA (e-mail: markivan@ prodigy.net).

Digital Object Identifier 10.1109/TEMC.2004.823617

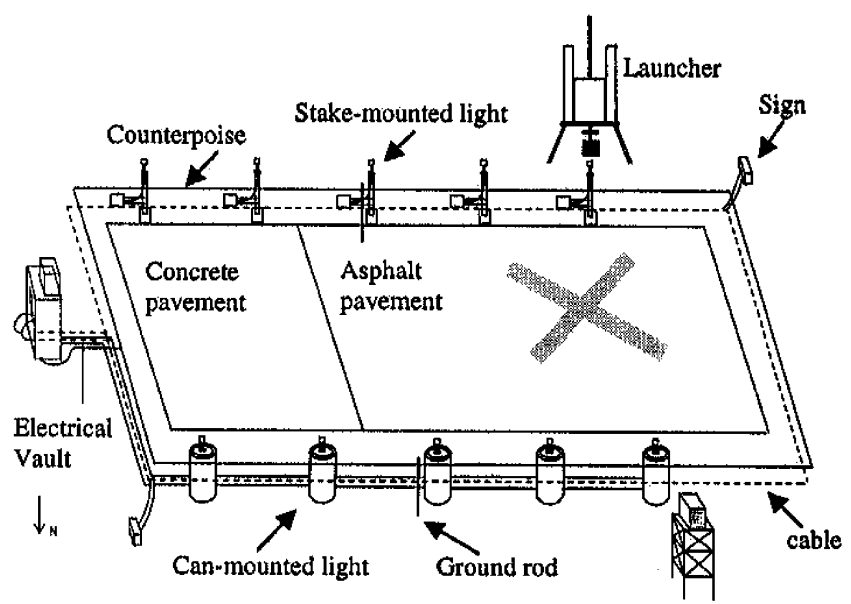

Fig. 1. Schematic representation of the runway and its lighting system. The horizontal dimensions of the lighting system are about $106 \mathrm{~m} \times 31 \mathrm{~m}$. The cable is buried at a depth of $0.4 \mathrm{~m}$ with the counterpoise placed in the same trench $0.1 \mathrm{~m}$ or so above the cable.

\section{EXPERIMENTAL SETUP}

\section{A. Runway Lighting System}

The runway is located in the southeastern part of the ICLRT. The pavement is approximately $100-\mathrm{m}$ long and $25-\mathrm{m}$ wide and oriented east-west. The eastern one-third of the pavement is concrete, and the western two-thirds asphalt, as shown in Fig. 1.

The lighting system includes a generator, a current regulator (CCR), both placed in the electrical vault, a buried series 6.6-A lighting cable feeding, via current transformers, five equally spaced stake-mounted lights on the south side of the runway, five equally spaced can-mounted lights on the north side, and two signs in the NE and SW corners, and a buried counterpoise placed above the cable and connected to three vertical ground rods (see Fig. 1). The cable is buried at a depth of about $0.4 \mathrm{~m}$ and at a horizontal distance of $3 \mathrm{~m}$ from the pavement edge, making a large loop around the runway. It is placed inside a PVC pipe on the north side and directly buried on the south side (see Fig. 1). The lighting cable is a single stranded copper conductor AWG 8 (diameter is $3.26 \mathrm{~mm}$ ) covered with XLPE (crosslinked polyethylene) insulation with rated basic insulation level (BIL) of $5 \mathrm{kV}$. It conforms to the requirements of the US Federal Aviation Administration (FAA) standard AC 150/5345-7, which gives the specifications for cables to be used in lighting systems of airport runways. The counterpoise, a \#6 buried bare copper wire with an outer diameter of $4.11 \mathrm{~mm}$, is placed $10 \mathrm{~cm}$ or so above the cable (in the same trench) and conforms to the requirements of the FAA standard AC 150/5370-10, which gives 


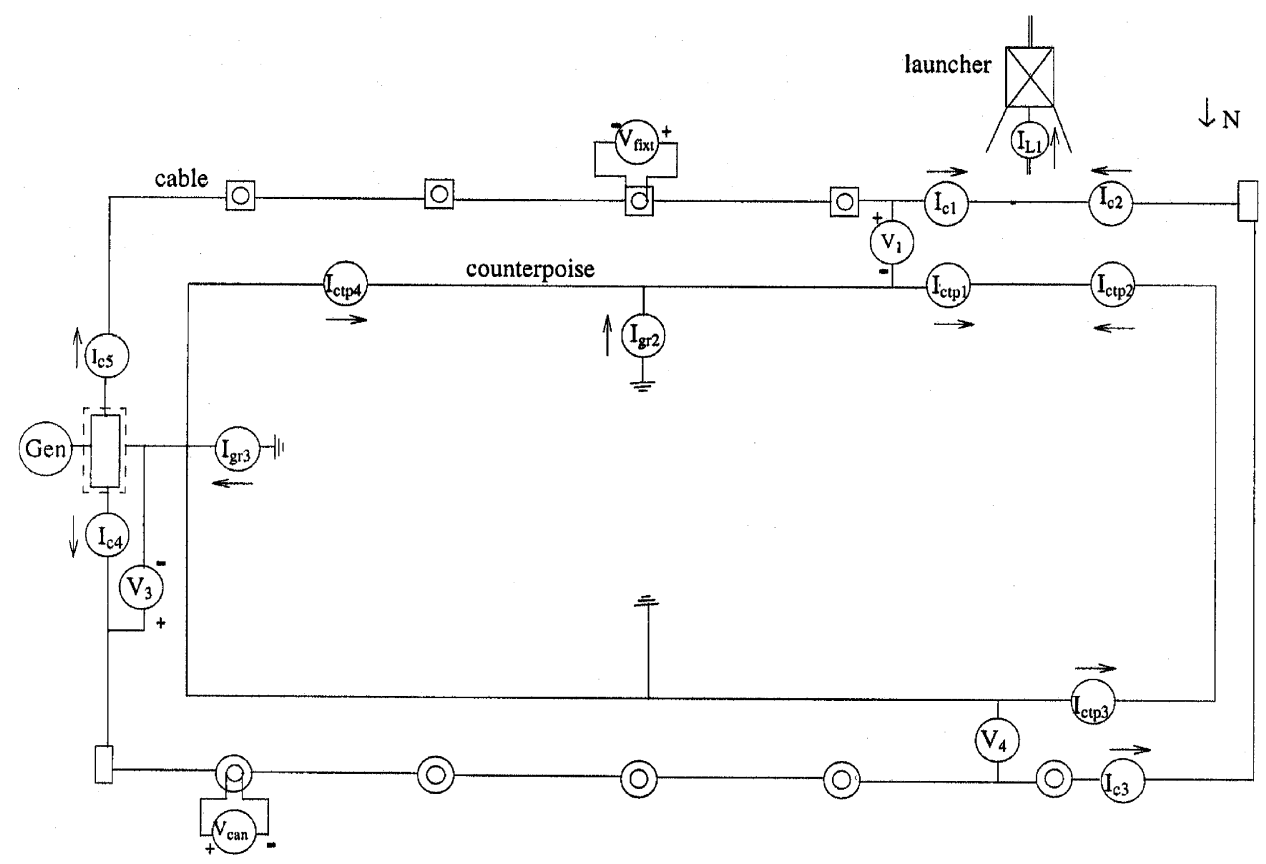

Fig. 2. Current and voltage measurement locations for configuration 4 .

TABLE I

CONFIGURATIONS OF THE TEST SYSTEM IN 1997-1998

\begin{tabular}{ccll}
\hline $\begin{array}{c}\text { Configuration } \\
\text { Number }\end{array}$ & Year & \multicolumn{1}{c}{ Position of the Launcher } & \multicolumn{1}{c}{ Remarks } \\
\hline 1 & 1997 & $\begin{array}{l}\text { On the concrete pavement at its } \\
\text { northern edge. }\end{array}$ & $\begin{array}{l}\text { The system was not energized. CCR was } \\
\text { replaced by a } 2 \Omega \text { resistor. }\end{array}$ \\
\hline 2 & 1997 & $\begin{array}{l}\text { Centered between the northern edge } \\
\text { of the concrete pavement and the } \\
\text { buried counterpoise. }\end{array}$ & $\begin{array}{l}\text { A metallic cable was used to connect the } \\
\text { launcher directly to the counterpoise. } \\
\text { System was not energized. }\end{array}$ \\
\hline 3 & $1997-$ & $\begin{array}{l}\text { At the south side off the asphalt } \\
\text { pavement, over the most westerly } \\
\text { stake-mounted light. }\end{array}$ & $\begin{array}{l}\text { System was either energized or not } \\
\text { energized. }\end{array}$ \\
\hline 4 & 1998 & $\begin{array}{l}\text { Same as for configuration 3, but with } \\
\text { one of the stake-mounted lights } \\
\text { being removed. }\end{array}$ \\
\hline
\end{tabular}

the specifications for the counterpoise. The counterpoise is connected, as shown in Fig. 1, to three vertical ground rods. Each ground rod is made of copper and has a diameter of $1.56 \mathrm{~cm}$ and a length of $2.4 \mathrm{~m}$. Ground rods on the south and north sides of the runway are each located approximately $55 \mathrm{~m}$ from the ground rod at the electrical vault (see Fig. 1).

\section{B. System Configurations}

In the summer of 1997, three different test configurations were used, as outlined in Table I. In configuration 1, the part of the system thought to be best protected was struck, that part containing the can-mounted lights with the current transformers placed inside the metallic cans and the cable between cans being inside PVC pipe. The launcher was located at the northern edge of the concrete pavement, and lightning current was injected into the concrete pavement via a short air gap. In configuration 2 , the launcher was moved from the pavement to a point on the ground centered between the northern edge of the runway and the counterpoise. A metallic cable was used to connect the launcher directly to the counterpoise, so that the total lightning current could be injected into the counterpoise. In configuration 3, the launcher was placed on the south side, off the asphalt pavement, so that it was directly over the westernmost stake-mounted light, as seen in Fig. 1. Tests using configuration 3 were begun at the end of summer 1997, and on September 26, 1997 one flash was initiated that lowered positive charge to ground and apparently did not contain return strokes. All other flashes lowered negative charge to ground. During summer 1998, tests began with configuration 3 , described above, and continued with configuration 4. In configuration 4 , the stake, the light, and the current transformer under the launcher were removed from the system, while the launcher remained at the same location in order to simulate lightning strikes to the earth's surface above the cable and the counterpoise. Thus, in configuration 4 , the systems contained five can-mounted and four stake-mounted lights. In the summer of 1998 tests, configuration 3 was subjected to four lightning strikes (three of them containing return strokes) and 


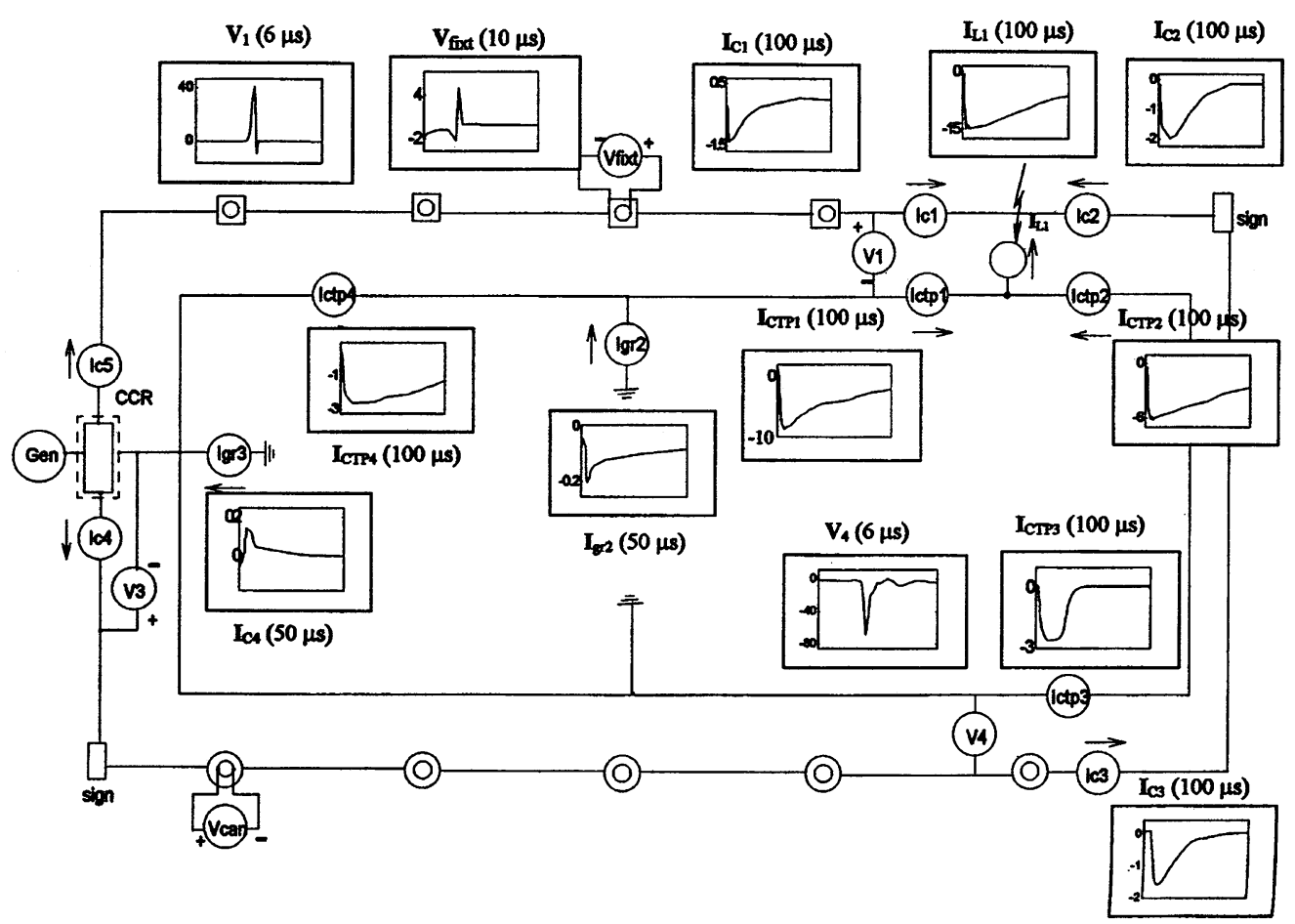

Fig. 3. Selected voltage (in kilovolts) and current (in kiloamperes) waveforms for configuration 4, Flash U9841, First Return Stroke. Times in parentheses indicate full scale.

configuration 4 to two strikes, both containing return strokes. In the following, we primarily consider system configuration 4, shown in Fig. 2, for which most of the data were obtained. A detailed description of data for all system configurations is found in Bejleri [3]. For configuration 4, we measured lightning channel current $\left(I_{L 1}\right)$, currents at four different locations along the counterpoise $\left(I_{\mathrm{ctp} 1}, I_{\mathrm{ctp} 2}, I_{\mathrm{ctp} 3}\right.$, and $\left.I_{\mathrm{ctp} 4}\right)$, currents at four different location along the cable $\left(I_{c 1}, I_{c 2}, I_{c 3}\right.$, and $\left.I_{c 4}\right)$, currents in ground rods $\left(I_{\mathrm{gr} 2}\right.$ and $\left.I_{\mathrm{gr} 3}\right)$, voltages between the cable and counterpoise at three different locations $\left(V_{1}, V_{3}\right.$, and $V_{4}$ ), voltage across can-mounted light bulb filament $\left(V_{\text {can }}\right)$, as well as the voltage between the metallic stake and the light bulb filament of one of the stake-mounted lights $\left(V_{\text {fixt }}\right)$ (see Fig. 2). Macrodyne lightning transient recorders (LTRs) with up to a 5-MHz sampling rate and Nicolet Pro 90 digitizing oscilloscopes with a sampling rate of 10 or $20 \mathrm{MHz}$ were used to measure the currents and the voltages. The $20-\mathrm{MHz}$ sampling rate was used for measuring $V_{1}$.

\section{DATA PRESENTATION}

We first present (in Section III-A) data for the first return stroke of Flash U9841 triggered on September 16, 1998. These data are representative of all measurements for configuration 4. Then, (in Section III-B), we present a summary of all the findings from the 1997-1998 experiments. Additional information is found in Bejleri [3].

\section{A. Case Study: Flash U9841, 1st Return Stroke}

The data for negative flash U9841 were obtained under test system configuration 4 (see Table I and Fig. 2). Flash U9841 produced four return strokes with peak currents of 15, 7.2,
3.8, and $11 \mathrm{kA}$. After the storm, the part of the system under the launcher was excavated and no damage to the cable was found. The counterpoise was melted at the point where the lightning attached to the system, and only two of the seven strands comprising the counterpoise remained continuous. The current transformer at the stake-mounted light close to the ground rod on the south side of the runway was found not to work properly after this flash and was replaced with a new one. The secondary cables of the damaged current transformer exhibited two pinholes and many burn marks on their surface. Selected current and voltage waveforms are shown in Fig. 3 and discussed below.

1) Total Lightning Current and Counterpoise Currents: The total lightning current $\left[I_{L 1}\right]$ for the first return stroke has a peak value of $15 \mathrm{kA}$ (see Fig. 3). The currents in the counterpoise at the east of launcher location $\left[I_{\mathrm{ctp} 1}\right]$, with a peak value of $8.8 \mathrm{kA}$, and west of launcher location $\left[I_{\mathrm{ctp} 2}\right]$, with a peak value of $6.0 \mathrm{kA}$, show characteristics similar to those of the lightning channel current. In particular, the risetimes are of the order of $1 \mu$ s or less.

The current at the NW location $\left[I_{\operatorname{ctp} 3}\right]$ increases to its negative peak value with a rise time similar to that of the total lightning current. Then, the current exhibits a plateau, which lasts approximately $12 \mu \mathrm{s}$, followed by a rapid decay to zero, with an overall pulse duration of $40 \mu \mathrm{s}$.

The current waveform at the south of the runway location $\left[I_{\mathrm{ctp} 4}\right]$, initially exhibits an increase to its negative peak value of $2.6 \mathrm{kA}$ with a rise time similar to the total lightning current risetime and decays similarly to the current measured at the east of launcher location. Current in ground rod $\left[I_{\mathrm{gr} 2}\right]$ at the south location has a negative peak of $200 \mathrm{~A}$, rise time of $0.6 \mu \mathrm{s}$, and accounts for only $1.3 \%$ of the total lightning current. 
2) Cable Currents: Cable currents were measured at four different locations for flash U9841. Currents $\left[I_{c 1}\right]$ and $\left[I_{c 2}\right]$, with peak values of 1.4 and $2.0 \mathrm{kA}$, respectively, have the same direction and rise time as $\left[I_{\mathrm{ctp} 1}\right]$ and $\left[I_{\mathrm{ctp} 2}\right]$. Current at the NW location $\left[I_{c 3}\right]$, has a peak value of $1.6 \mathrm{kA}$. Current at the Electrical Vault location $\left[I_{c 4}\right]$ has much smaller peak value than $\left[I_{c 1}\right]$, $\left[I_{c 2}\right]$, and $\left[I_{c 3}\right]$.

3) Voltages: Voltage waveforms for the first return stroke of Flash U9841 include voltages measured between the cable and the counterpoise at the east of the launcher location $\left[V_{1}\right]$, NW location $\left[V_{4}\right]$, and the voltage between the light fixture and the light bulb filament at one of the stake-mounted lights $\left[V_{\text {fixt }}\right]$.

The voltage between the cable and the counterpoise $3 \mathrm{~m}$ east of the launcher, $\left[V_{1}\right]$, is recorded with a sampling interval of $50 \mathrm{~ns}$. The voltage has a positive peak of $40 \mathrm{kV}$ and a negative peak of $9 \mathrm{kV}$. The voltage reaches a positive peak in $150 \mathrm{~ns}$ (the cable has a higher potential than the counterpoise) and then a negative peak (the counterpoise has a higher potential than the cable). The time interval between the positive and negative peaks is $50 \mathrm{~ns}$, equal to the sampling interval, so that the actual voltage peaks are likely to be higher. The voltage waveform has a duration of only $200 \mathrm{~ns}$. The voltage between the cable and the counterpoise at the NW location $\left[V_{4}\right]$ has a negative peak of $68 \mathrm{kV}$. The voltage waveform reaches its negative peak in $200 \mathrm{~ns}$ (the counterpoise has a higher potential than the cable) and has a duration of only about 3-4 $\mu$ s.

\section{B. Overall Results, 1997-1998}

1) Current Decay Along the Counterpoise: When lightning struck a stake-mounted light or directly struck the counterpoise, 10 to $30 \%$ of the total lightning current was dissipated locally, within $3 \mathrm{~m}$ of the strike point (from measurements made at a distance of $3 \mathrm{~m}$ on either side of the strike point), while 70 to $90 \%$ was carried by the counterpoise further away from the strike point. Measurements of the counterpoise current at four different locations (two on each side of the strike point) made it possible to estimate that about $63 \%$ of the current detected $3 \mathrm{~m}$ from the strike point was dissipated in the ground after propagating along $50 \mathrm{~m}$ of the counterpoise, and about $73 \%$ of the current detected $3 \mathrm{~m}$ on the other side from the strike point was dissipated in the ground after propagating along $67 \mathrm{~m}$ of the counterpoise. The average percent current decay rate is about $1 \%$ per meter, independent of the peak current at the origin (peak current measured $3 \mathrm{~m}$ from the strike point), as illustrated in Fig. 4. The current waveshape changes as the current wave propagates along the counterpoise: while the rise time remains more or less the same, a plateau or a broad maximum, not seen in the total lightning current waveform, is observed at distances of 50 and $67 \mathrm{~m}$. The plateau duration is approximately between 10 and $50 \mu \mathrm{s}$. In some cases, when the lightning current is smaller than $10 \mathrm{kA}$, current waveforms do not exhibit the plateau.

2) Currents in Ground Rods: During experiments with configurations 1 and 2, the entry point of current in the counterpoise was about $12 \mathrm{~m}$ from the north ground rod. In this case, the current through the ground rod was as high as 1 to $2 \mathrm{kA}$, accounting for 10 to $15 \%$ of the total lightning current.

During experiments with configurations 3 and 4 , the entry point of current in the counterpoise was about $36 \mathrm{~m}$ from the
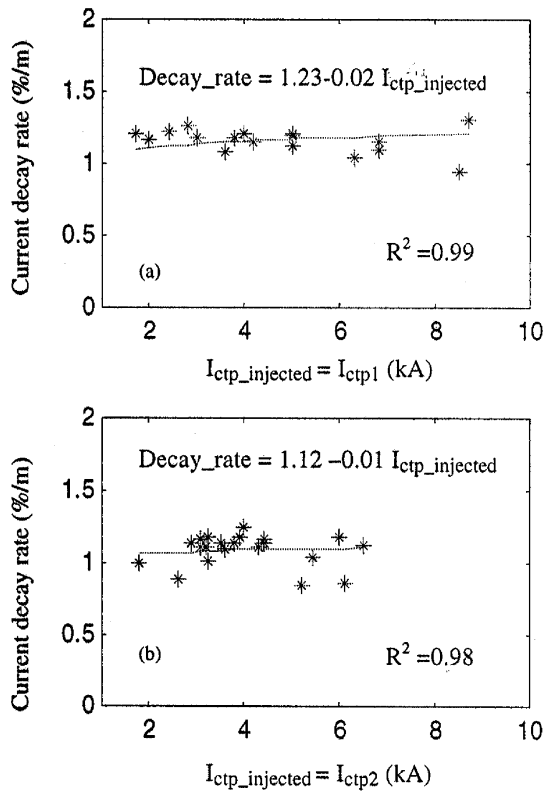

Fig. 4. Decay rate of current in percent per meter length of the counterpoise (a) east of the launcher and (b) west of the launcher as a function of peak current measured $3 \mathrm{~m}$ from the strike point and labeled $I_{\text {ctp_injected }}$.
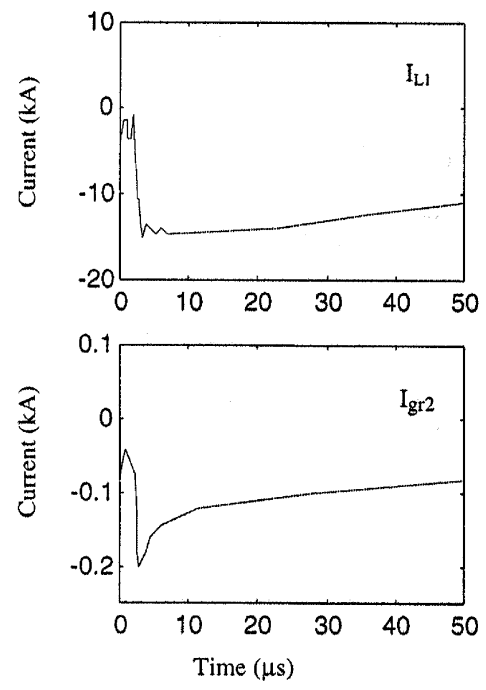

Fig. 5. Lightning channel current $\left[I_{L 1}\right]$ and ground rod current $\left[I_{\mathrm{gr} 2}\right]$ for Flash U9841, first return stroke.

south ground rod. Shown in Fig. 5 are the waveforms of the lightning channel current and the current through the ground rod for the first return stroke of Flash U9841. In this particular case the current through the ground rod accounts for approximately $1.3 \%$ of the lightning channel current (peak values). For all the lightning strikes $36 \mathrm{~m}$ from the south ground rod, the maximum value of current leaving the system through this ground rod was about $300 \mathrm{~A}$, which was less than $5 \%$ of the total lightning current. The ground rod current waveform has approximately the same risetime as the lightning current but it has shorter duration. This suggests that the ground rod is a better path than the counterpoise for the higher frequency components in the current. Rakov et al. [4], who also observed very different current waveshapes in different parts of their test system, recommend 
charge transfer as a better quantity (than the peak current) for the examination of lightning current sharing in the system.

3) Cable Currents: From the data recorded, it appears that the current flowing in the counterpoise induces current in the cable. The largest currents in the cable are observed near the current injection point.

4) Lightning Damage to the System: Several elements of the test airport runway lighting system sustained damage caused by one or more lightning strikes. The damage includes: 1) failure of one of the electronic boards of the CCR;2) minor damage to the light fixture and to the glass cover of the light bulb of the stake-mounted light under the launcher; 3) multiple burn marks on the surface of the secondary cable of the current transformers (at the strike point and at distance of $36 \mathrm{~m}$ from it); 4) pinholes on the secondary cable of the current transformer; and 5) melting of the counterpoise conductor at the point where the lightning attached to the system. No evidence of direct lightning current injection into the cable or flashover to the cable from the counterpoise was found, but they definitely cannot be ruled out.

\section{CONCLUSION}

When lightning strikes a stake-mounted light or directly strikes the counterpoise, the counterpoise carries the bulk of the total lightning current away from the strike point. The current flowing in the counterpoise decays at a rate of about $1 \%$ per meter. Vertical ground rods connected beyond several meters from the strike point dissipate a relatively small fraction of the total lightning current. Currents in the vertical ground rods exhibit considerably narrower waveforms than the injected lightning current.

\section{REFERENCES}

[1] M. A. Uman, V. A. Rakov, K. J. Rambo, T. W. Vaught, M. I. Fernandez, D. J. Cordier, R. M. Chandler, R. Bernstein, and C. Golden, "Triggeredlightning experiments at Camp Blanding, Florida (1993-1995)," Trans. IEE Japan, vol. 117-B, no. 4, pp. 446-452, 1997.

[2] V. A. Rakov, M. A. Uman, K. J. Rambo, M. I. Fernandez, R. J. Fisher, G. H. Schnetzer, R. Thottappillil, A. Eybert-Berard, J. P. Berlandis, P. Lalande, A. Bonamy, P. Laroche, and A. Bondiou-Clergerie, "New insights into lightning processes gained from triggered lightning experiments in Florida and Alabama," J. Geophys. Res., vol. 103, no. D12, pp. 14 117-14 130, 1998.

[3] M. Bejleri, "Triggered-Lightning Testing of an Airport Runway Lighting System,” Master's thesis, Dept. Elect. Comp. Eng., University of Florida, Gainesville, 1999.

[4] V. A. Rakov, M. A. Uman, M. I. Fernandez, C. T. Mata, K. J. Rambo, M. V. Stapleton, and R. R. Sutil, "Direct lightning strikes to the lightning protective system of a residential building: Triggered-lightning experiments," IEEE Trans. Power Delivery, vol. 17, pp. 575-586, Apr. 2002.

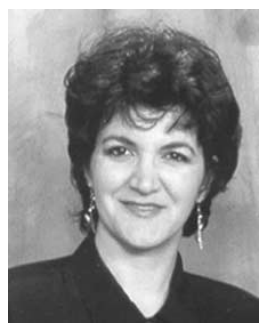

Mirela Bejleri received the Bachelor's degree from the "Polytechnic University of Tirana," Tirana, Albania, and the M.Sc. degree from the Department of Electrical and Computer Engineering, University of Florida, Gainesville, in in 1990, and 1999, respectively.

From 19991 to 1995 , she was an Assistant Professor of Electrical Engineering at the "Polytechnic University of Tirana." Currently, she is a Senior Software Engineer with the iDEN Subscriber Division, Motorola Inc, Plantation, FL. She specializes in wireless protocol implementation for embedded devices.

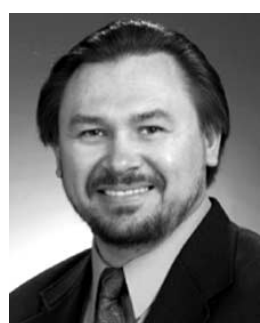

Vladimir A. Rakov (SM'96-F'03) received the Master's and Ph.D. degrees from Tomsk Polytechnical University (Tomsk Polytechnic), Tomsk, Russia in 1977 and 1983, respectively.

From 1977 to 1979, he was an Assistant Professor of Electrical Engineering at Tomsk Polytechnic. In 1978, he became involved in lightning research at the High Voltage Engineering, a division of Tomsk Polytechnic, where from 1984 to 1994, he held the position of Director of the Lightning Research Laboratory. In 1985, he received the rank of Senior Scientist the High Voltage Research Institute. In 1991, he joined the faculty of the Department of Electrical and Computer Engineering at the University of Florida (UF), Gainesville, where he is a Professor in the Department of Electrical and Computer Engineering. He is the author or coauthor of over 30 patents, the book Lightning: Physics and Effects (Cambridge, U.K.: Cambridge Univer. Press, 2003), and about 300 papers and technical reports on various aspects of lightning, with over 100 papers published in reviewed journals.

Dr. Rakov has been named an Inventor of the USSR (1986) and received a Silver Medal from the (USSR) National Exhibition of Technological Achievements (1987). He is a Fellow of the American Meteorological Society, Chairman of the Technical Committee on Lightning of the biennial International Zurich Symposium on Electromagnetic Compatibility, and former chairman of the AGU Committee on Atmospheric and Space Electricity.

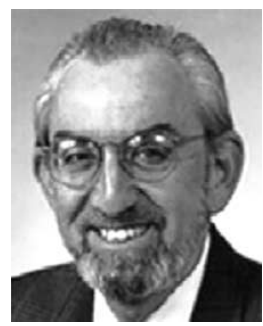

Martin A. Uman (SM'73-F'88) received the Ph.D. degree from Princeton University, Princeton, NJ, in 1961.

He was an Associate Professor of Electrical Engineering at the University of Arizona, Tucson, from 1961 to 1964 . He joined the University of Florida's (UF) faculty in 1971 after working for seven years as a Fellow Physicist at Westinghouse Research Labs, Pittsburgh, PA. He cofounded and served as President of Lightning Location and Protection Inc. (LLP), Tucson, AZ, from 1975 to 1985. He was the Professor and Chair of the UF Department of Electrical and Computer Engineering, from 1999-2003, and is now Distinguished Professor. He has written four books on the subject of lightning, as well as a book on plasma physics, ten book chapters and encyclopedia articles on lightning, and has published over 140 papers in reviewed journals. He holds five patents, four in the area of lightning detection.

Dr. Uman is the recipient of the 1996 IEEE Heinrich Hertz Medal for outstanding contributions to the understanding of lightning electromagnetics and its application to lightning detection and protection," and the 2001 AGU John Adam Fleming Medal for original research and technical leadership in geomagnetism, atmospheric electricity, space science, aeronomy, and related sciences: for outstanding contribution to the description and understanding of electricity and magnetism of the Earth and its atmosphere." He is a Fellow of the American Geophysical Union (AGU) and the American Meteorological Society (AMS).

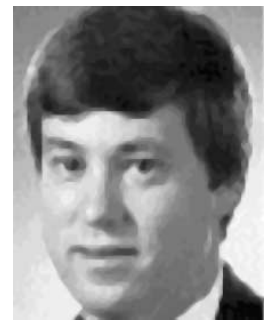

Keith J. Rambo received the B.S.E.E. degree from the University of Florida (UF), Gainesville, in 1978.

As an undergraduate, he worked in the UF Lightning Research Laboratory. From 1979 to 1983, he was a Senior Process Development Engineer of Intel Corporation, Santa Clara, CA. From 1983 through 1986 he was a Product Line Manager for Xicor, Milpitas, CA, responsible for all aspects of wafer fabrication. In 1986, he joined the UF Department of Electrical and Computer Engineering, where, since 1989, he has been Director of Technical Support Services. Since 1994, Mr. Rambo has been heavily involved in triggered-lightning experiments at Camp Blanding, Florida. He has ten technical publications. 


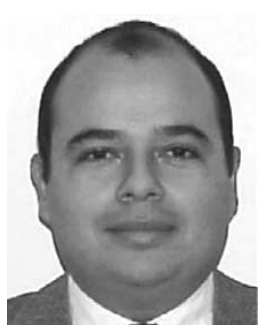

Carlos T. Mata (S'98-M'01) received the Bachelor's degree from the "Universidad Simón Bolívar" (USB), Venezuela in 1993, and the Master's and $\mathrm{Ph} . \mathrm{D}$. degrees from the University of Florida (UF), Gainesville in 1997 and 2000, respectively.

He currently works at the Kennedy Space Center, FL, doing embedded system and advanced data acquisition systems design in support to the Shuttle program. He is involved in the area of computer modeling of different lightning processes and responses of power distribution systems to direct and nearby lightning strikes. He is author or coauthor of eight journal publications and eight technical reports.

In 1998, Dr. Mata received the GAANN fellowship and in 2001 the IEEE Power Engineering Society SPDC Prize Paper Award and the Kennedy Space Center Innovative Excellence Award. He is a member of the American Geophysical Union (AGU) and the Power Engineering Society (PES).

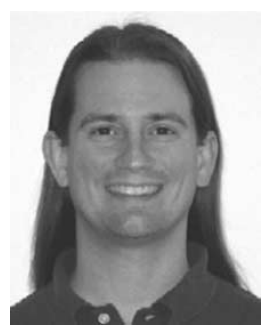

Mark I. Fernandez received the Bachelor's degree from Florida Institute of Technology (FIT), Melbourne, in 1995, and the Master's degree from the University of Florida (UF), Gainesville, in 1997.

$\mathrm{He}$ was involved in magnetospheric and space plasma research as an undergraduate in the Department of Physics and Space Sciences at FIT. From 1995 to 1997, he held a graduate research assistantship in the UF Lightning Research Laboratory. He is author or coauthor of eight publications (including one in press) in reviewed journals, fifteen published abstracts or conference proceedings, and six technical reports. He is an Engineer in the U.S. Department of Defense, Fort Mead, MD. 